\section{OP0058 CARDIOVASCULAR AND CEREBROVASCULAR RISK IN PATIENTS WITH SMALL VESSEL VASCULITIDES: A COMPARATIVE ANALYSIS BETWEEN AORTIC STIFFNESS, CAROTID SONOGRAPHY AND SCORE}

K. Triantafyllias ${ }^{1}$, L. E. Thiele ${ }^{2}$, M. De Blasi ${ }^{1}$, A. Schwarting ${ }^{2,3} .{ }^{1}$ ACURA Clinics, Rheumatology, Bad Kreuznach, Germany; ${ }^{2} J o h a n n e s$ Gutenberg University Medical Center, Internal Medicine I, Department of Rheumatology and Clinical Immunology, Mainz, Germany; ${ }^{3}$ ACURA Clinics, Rheumatology, 55543, Germany

Background: Cardiovascular (CV) and cerebrovascular (CVB) risk have not been adequately examined in the setting of patients with small vessel vasculitides. In particular, data on CV/CVB surogate markers are scarce and the diagnostic value of traditional CV risk scores, such as the Systematic COronary Risk Evaluation (SCORE) and ist EULAR modified version (mSCORE) is unknown. Objectives: Aims of this study were to examine gold standard surrogates of CV risk and subclinical atherosclerosis (1), as well as novel duplex-sonographic markers of CVB risk in a cohort of patients with small vessel vasculitides. Moreover, we sought to evaluate for the first time the diagnostic value of SCORE and mSCORE in identifying patients at high CV and CVB risk.

Methods: SCORE/mSCORE and the gold standard marker of aortic stiffness (carotid-femoral pulse wave velocity; cfPWV) were examined in patients with small vessel vasculitides and healthy controls across 3 Rheumatology Centers. Moreover, sonography of the common- (CCA), internal- (ICA) and external- (ECA) carotid arteries was performed in subsets of both groups, evaluating carotid intima-media-thickness (CIMT), plaque presence and duplex-sonographic indices of CBV risk, such as the resistance- $(\mathrm{RI})$ and pulsatility-index $(\mathrm{PI})$. Disease characteristics, clinical and serological activity markers, as well as traditional $\mathrm{CV}$ risk factors were also documented. Results: We recruited 46 patients with small vessel vasculitides [granulomatosis with polyangiitis $(n=33)$, eosinophilic granulomatosis with polyangiitis $(n=6)$, microscopic polyangiitis $(n=4)$, cryoglobulinemic vasculitis $(n=1)$, urticaria vasculitis $(n=2): 76.1 \%$ female, median age 61.5 years $(52-72.25$, IQR)] and 105 healthy controls [76.1\% female, median age 61.5 years $(52-72.25$, IQR)]. cfPWV was significantly higher in the patient group compared to the control group, even after statistical corrections for confounding factors (i.e. age, gender: different in the two groups) $\left(8.4 \mathrm{~m} / \mathrm{s}\right.$ vs. $\left.6.8 \mathrm{~m} / \mathrm{s} ; \mathrm{p}_{\text {adj }}<0.001\right)$. Moreover, carotid sonography revealed higher CVB surrogates in the patient subgroup, compared to controls. According to SCORE and (EULAR)-mSCORE, $0.9 \%$ and $15.8 \%$ of the patients had high CV risk (defined as SCORE/mSCORE $>5$ ), respectivelly. However, cfPWV revealed an increased CV risk in $28.2 \%$ of the patients. Moreover, carotid sonography showed signs of subclinical carotid arteriosclerosis in $50 \%$ (plaques) and $71.7 \%$ (cIMT $>0.9 \mathrm{~mm}$ ) of the patients, respectively.

Conclusion: Herein, we could show that patients with small vessel vasculitides had higher aortic stiffness and subclinical carotid atherosclerosis, compared to controls and could thus have higher CV and CVB risk. Moreover, we were able to demonstrate for the first time that SCORE/mSCORE performed poorly in identifying patients at high CV risk and carotid atherosclerosis compared to cfPWV and carotid sonography respectively. Thus, cfPWV and carotid sonography could improve CV and CBV screening in patients with small vessel vasculitides.

Table 1. Descriptive characteristics.

\begin{tabular}{|c|c|c|c|}
\hline & $\begin{array}{l}\text { Controls } \\
(n=105)\end{array}$ & $\begin{array}{l}\text { Patients } \\
(n=46)\end{array}$ & $\begin{array}{c}\text { Significance } \\
\text { (p) }\end{array}$ \\
\hline $\operatorname{cfPWV} \dagger(\mathrm{m} / \mathrm{s})$ & $6.80(6.05-7.5)$ & $8.40(7.26-10.66)$ & $<0.001^{*}$ \\
\hline Aget (years) & $50(39.50-56.5)$ & $61.50(52-72.25)$ & $<0.001^{*}$ \\
\hline Gender (female) & $95(90.5 \%)$ & $35(76.1 \%)$ & $0.019^{\star}$ \\
\hline Nicotin (smokers) & $21(20 \%)$ & $5(11.1 \%)$ & 0.190 \\
\hline Antihypertensive drugs & $18(17.1 \%)$ & $27(65.9 \%)$ & $<0.001^{*}$ \\
\hline BMI $\dagger$ & $23.73(21.1-27.1)$ & $25.14(22.81-28.70)$ & 0.074 \\
\hline Mean art. pressureף & $93.45 \pm 10.68$ & $96.19 \pm 10.68$ & 0.150 \\
\hline $\operatorname{ESR} \dagger(\mathrm{mm} / \mathrm{h})$ & - & $20.00(11-41.5)$ & - \\
\hline ANCA & - & $25(54.3 \%)$ & - \\
\hline Creatinine $\dagger$ & $0.77(0.72-0.81)$ & $0.94(0.8-1.31)$ & $<0.001^{*}$ \\
\hline Cholesterolๆ ( $\mathrm{mg} / \mathrm{dL})$ & - & $216.88 \pm 40.16$ & - \\
\hline Prednisolone $(\mathrm{mg})$ & - & $5.63(1.75-16.38)$ & - \\
\hline Lung involvement & & $17(37 \%)$ & - \\
\hline Kidney involvement & & $17(37 \%)$ & - \\
\hline Ear-nose-throat (ENT) & & $16(34.8 \%)$ & - \\
\hline
\end{tabular}

†median (IQR): Mann Whitney test 7 mean \pm standard deviation: $t$ test ${ }^{*} \mathrm{p}<0.05$

\section{REFERENCES:}

[1] Vlachopoulos C et al., Prediction of Cardiovascular Events and All-Cause Mortality With Arterial Stiffness: A Systematic Review and Meta-Analysis. J Am Coll Cardiol 2010 30;55(13):1318-27

Disclosure of Interests: Konstantinos Triantafyllias Speakers bureau: Pfizer, Novartis, Janssen, Chugai, Leif-Erik Thiele: None declared, Michele De Blasi: None declared, Andreas Schwarting: None declared

DOI: 10.1136/annrheumdis-2021-eular.3603

\section{OP0059 \\ MAVRILIMUMAB (ANTI GM-CSF RECEPTOR A MONOCLONAL ANTIBODY) REDUCES RISK OF FLARE AND INCREASES SUSTAINED REMISSION IN A PHASE 2 TRIAL OF PATIENTS WITH GIANT CELL ARTERITIS}

M. C. Cid ${ }^{1}$, S. Unizony ${ }^{2}$, L. Pupim ${ }^{3}$, F. Fang ${ }^{3}$, J. Pirrello ${ }^{4}$, A. Ren ${ }^{5}$, M. Samant ${ }^{3}$, T. Zhou ${ }^{3}$, J. F. Paolini ${ }^{3}{ }^{1}{ }^{1}$ Hospital Clínic, University of Barcelona, Institut d'Investigacions Biomèdiques August Pi i Sunyer (IDIBAPS), Vasculitis Research Unit, Department of Autoimmune Diseases, Barcelona, Spain; ${ }^{2}$ Massachusetts General Hospital, Vasculitis and Glomerulonephritis Center, Department of Rheumatology, Allergy and Immunology, Boston, United States of America; ${ }^{3}$ Kiniksa Pharmaceuticals Corp., Clinical Development, Lexington, United States of America; ${ }^{4}$ Kiniksa Pharmaceuticals Corp., Business Development, Lexington, United States of America; ${ }^{5}$ Kiniksa Pharmaceuticals Corp., Clinical Operations, Lexington, United States of America

Background: T helper (Th)1 and Th17 lymphocytes play a role in the pathogenesis of giant cell arteritis (GCA). Current treatments primarily target the Th17 axis, possibly leaving residual Th1 activity. Granulocyte macrophage colony stimulating factor (GM-CSF), a mediator of Th1 and Th17 cells, is a pathogenic factor in GCA Objectives: To evaluate the efficacy and safety of the GM-CSF inhibitor mavrilimumab in patients with GCA.

Methods: Randomized, double-blind, placebo-controlled phase 2 trial enrolling patients with active, biopsy- or imaging-proven new onset (N/O) or relapsing refractory (R/R) GCA. Active disease: GCA symptoms and erythrocyte sedimentation rate (ESR) $(>30 \mathrm{~mm} / \mathrm{hr}$ ) and/or C-reactive protein (CRP) $(\geq 1 \mathrm{mg} / \mathrm{dL})$ elevation within 6 weeks from randomization. Corticosteroid-induced remission (resolution of GCA symptoms and CRP $<1 \mathrm{mg} / \mathrm{dL}$ or ESR $<20 \mathrm{~mm} / \mathrm{hr}$ ) was required by baseline. $3: 2$ randomization to mavrilimumab $150 \mathrm{mg}$ or placebo subcutaneously every 2 weeks and protocol-defined 26-week prednisone taper starting at 20-60 mg/day. Primary efficacy endpoint: time to first adjudicated flare $(E S R \geq 30 \mathrm{~mm} / \mathrm{hr}$ and/ or CRP $\geq 1 \mathrm{mg} / \mathrm{dL}$ and GCA symptoms or new/worsening vasculitis on imaging) by Week 26 in all treated patients. Key secondary endpoint: sustained remission through Week 26. Safety up to Week 38 was assessed.

Results: 70 patients ( $35 \mathrm{~N} / \mathrm{O}, 35 \mathrm{R} / \mathrm{R}$ ) were enrolled (mavrilimumab [N=42] or placebo [N=28]). Mean (SD) age was $69.7(7.48)$ years and $71.4 \%$ were female. Flare by Week 26 occurred in $8(19 \%)$ and $13(46.4 \%)$ patients receiving mavrilimumab and placebo, respectively (27.4 percentage points reduction). Median time to flare by Week 26 could not be estimated in the mavrilimumab group due to too few events (Not Estimable) and was 25.1 weeks $[95 \% \mathrm{Cl}$ : (16.0, NE)] in the placebo group (HR [95\% Cl] $0.38[0.15,0.92]$; p=0.0263) (Figure). Sustained remission at Week 26 occurred in $83.2 \%$ of patients receiving mavrilimumab and $49.9 \%$ of those receiving placebo (33.4 percentage points increase; $p=0.0038$ ). Results were consistent across disease type subgroups (HR for flare: N/O 0.29 [95\% Cl: 0.06, 1.31; nominal $p=0.0873$ ]; R/R 0.43 [95\% Cl: $0.14,1.30]$; nominal $p=0.1231$ ), although not powered for significance (Table). Adverse events (AEs), mostly mild to moderate, were comparable between groups. There were 5 serious AEs (mavrilimumab 2 [4.8\%], placebo 3 [10.7\%]), none drug-related. No deaths or vision loss occurred. No adjudicated cases of pulmonary alveolar proteinosis were observed.

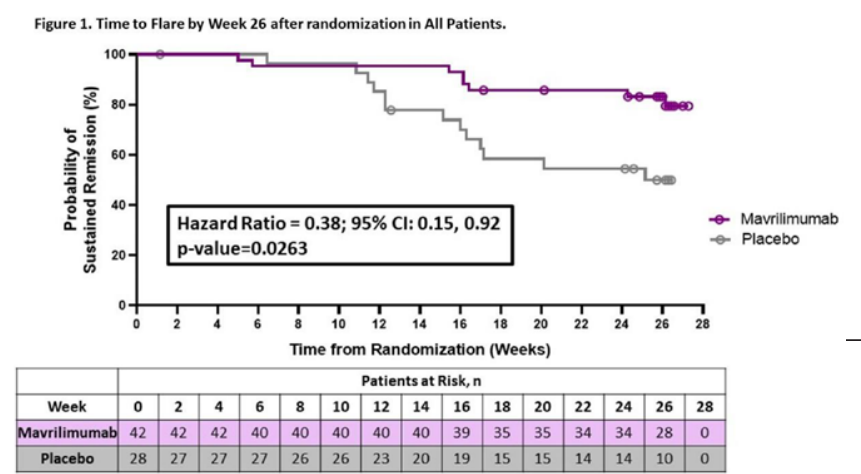

Conclusion: Mavrilimumab was superior to placebo on the primary and secondary efficacy endpoints of time to flare and sustained remission at week 26 in patients with GCA. Mavrilimumab was well tolerated, and no new safety signals were observed.

Disclosure of Interests: Maria C. Cid Speakers bureau: meeting attendance support from Roche and Kiniksa, Paid instructor for: educational from GSK and Vifor, Consultant of: consulting for Janssen, GSK, and Abbvie, Grant/research support from: research grant from Kiniksa, Sebastian Unizony Consultant of: consulting for Janssen and Kiniksa, Grant/research support from: research support from Genentech, Lara Pupim Shareholder of: Kiniksa Pharmaceuticals, Employee of: Kiniksa Pharmaceuticals, Fang Fang Shareholder of: Kiniksa Pharmaceuticals, Employee of: Kiniksa Pharmaceuticals, Joseph Pirrello Shareholder of: Kiniksa 
Table 1. Efficacy at Week 26

\begin{tabular}{|c|c|c|c|c|c|c|}
\hline & \multirow{2}{*}{\multicolumn{2}{|c|}{ All Patients [1] }} & \multicolumn{4}{|c|}{ Subgroups } \\
\hline & & & \multicolumn{2}{|c|}{$\mathrm{N} / \mathrm{O}$} & \multicolumn{2}{|c|}{$R / R$} \\
\hline & $\begin{array}{l}\text { Mavrilimu- } \\
\text { mab (N=42) }\end{array}$ & $\begin{array}{c}\text { Placebo } \\
(\mathrm{N}=28)\end{array}$ & $\begin{array}{l}\text { Mavrilimu- } \\
\text { mab (N=24) }\end{array}$ & $\begin{array}{c}\text { Placebo } \\
(\mathrm{N}=11)\end{array}$ & $\begin{array}{l}\text { Mavrilimu- } \\
\text { mab (N=18) }\end{array}$ & $\begin{array}{c}\text { Placebo } \\
(\mathrm{N}=17)\end{array}$ \\
\hline $\begin{array}{l}\text { Patients with } \\
\text { Flare, } \mathrm{n}(\%)\end{array}$ & $8(19.0)$ & $13(46.4)$ & $3(12.5)$ & $4(36.4)$ & $5(27.8)$ & 9 (52.9) \\
\hline \multicolumn{7}{|c|}{ Time to Flare (weeks) [2] } \\
\hline Median, $95 \% \mathrm{Cl}$ & $\begin{array}{c}\text { NE } \\
(\mathrm{NE}, \mathrm{NE})\end{array}$ & $\begin{array}{c}25.1 \\
(16.0, \mathrm{NE})\end{array}$ & $\begin{array}{c}\mathrm{NE} \\
(\mathrm{NE}, \mathrm{NE})\end{array}$ & $\begin{array}{c}\mathrm{NE} \\
(11.7, \mathrm{NE})\end{array}$ & $\begin{array}{c}\mathrm{NE} \\
(16.4, \mathrm{NE})\end{array}$ & $\begin{array}{c}22.6 \\
(16.0, \mathrm{NE})\end{array}$ \\
\hline $\begin{array}{l}\text { HR (Mavrilimumab } \\
\text { vs Placebo), } \\
95 \% \mathrm{Cl}[3]\end{array}$ & $\begin{array}{c}0.38 \\
(0.15,0.92)\end{array}$ & & $\begin{array}{c}0.29 \\
(0.06,1.31)\end{array}$ & & $\begin{array}{c}0.43 \\
(0.14,1.30)\end{array}$ & \\
\hline P-value [4] [5] & 0.0263 & & 0.0873 & & 0.1231 & \\
\hline $\begin{array}{l}\text { Sustained } \\
\text { Remission (\%), } \\
95 \% \mathrm{Cl}[6]\end{array}$ & $\begin{array}{c}83.2 \\
(67.9,91.6)\end{array}$ & $\begin{array}{c}49.9 \\
(29.6,67.3)\end{array}$ & $\begin{array}{c}91.3 \\
(69.3,97.7)\end{array}$ & $\begin{array}{c}62.3 \\
(27.7,84.0)\end{array}$ & $\begin{array}{c}72.2 \\
(45.6,87.4)\end{array}$ & $\begin{array}{c}41.7 \\
(17.4,64.5)\end{array}$ \\
\hline $\begin{array}{l}\text { Difference in } \\
\text { Proportions } \\
(95 \% \mathrm{Cl})[7]\end{array}$ & $\begin{array}{c}33.3 \\
(10.7,55.8)\end{array}$ & & $\begin{array}{c}28.9 \\
(-2.7,60.5)\end{array}$ & & $\begin{array}{c}30.6 \\
(-2.1,63.2)\end{array}$ & \\
\hline P-value [5] [7] & 0.0038 & & 0.0727 & & 0.0668 & \\
\hline
\end{tabular}

NE = Not estimable.[1] Total mITT population. Stratified by randomization strata.[2] Kaplan-Meier.[3] Cox proportional-hazards model; treatment as covariate.[4] Logrank test.[5] N/O and R/R subgroups not powered for significance; nominal $p$ values reported.[6] Kaplan-Meier Survival Estimates with standard error.[7] Two-sided p-value for the difference in sustained remission between 2 arms using normal approximation. Placebo arm is reference.

Pharmaceuticals, Employee of: Kiniksa Pharmaceuticals, Ai Ren Shareholder of: Kiniksa Pharmaceuticals, Employee of: Kiniksa Pharmaceuticals, Manoj Samant Shareholder of: Kiniksa Pharmaceuticals, Employee of: Kiniksa Pharmaceuticals, Teresa Zhou Shareholder of: Kiniksa Pharmaceuticals, Employee of: Kiniksa Pharmaceuticals, John F. Paolini Shareholder of: Kiniksa Pharmaceuticals, Employee of: Kiniksa Pharmaceuticals DOI: 10.1136/annrheumdis-2021-eular.1915

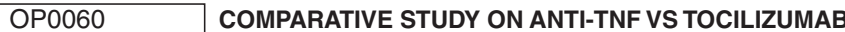 FOR TREATMENT OF REFRACTORY UVEITIC CYSTOID MACULAR EDEMA DUE TO BEHCET'S DISEASE. MULTICENTER STUDY OF 49 PATIENTS}

B. Atienza-Mateo ${ }^{1}$, I. Ferraz-Amaro², E. Beltrán ${ }^{3}$, A. Adan ${ }^{4}$, M. HernándezGarfella $^{5}$, L. Martinez-Costa ${ }^{6}$, M. Cordero-Coma ${ }^{7}$, M. Díaz-Llopis ${ }^{8}$, J. M. Herreras ${ }^{9}$, O. Maiz-Alonso ${ }^{10}$, I. Torre-Salaberri ${ }^{11}$, D. Díaz Valle ${ }^{12}$, A. AtanesSandoval $^{13}$, F. Francisco ${ }^{14}$, S. Insua ${ }^{15}$, J. Sánchez $^{16}$, R. Almodovar ${ }^{17}$, O. Ruiz-Moreno ${ }^{18}$, M. Gandia Martinez ${ }^{19}$, J. M. Nolla ${ }^{20}$, J. L. Martín-Varillas ${ }^{21}$, V. Calvo-Río ${ }^{1}$, D. Prieto-Peña ${ }^{1}$, M. A. González-Gay ${ }^{1}$, R. Blanco ${ }^{1}$. ${ }^{1}$ Hospital Universitario Marqués de Valdecilla, IDIVAL, Rheumatology, Santander, Spain; ${ }^{2}$ Hospital Universitario de Canarias, Rheumatology, Santa Cruz de Tenerife, Spain; ${ }^{3} \mathrm{Hospital}$ del Mar, Rheumatology, Barcelona, Spain; ${ }^{4} \mathrm{Hospital}$ Clinic, Ophthalmology, Barcelona, Spain; ${ }^{5}$ Hospital General Universitario de Valencia, Ophthalmology, Valencia, Spain; ${ }^{6}$ Hospital Peset, Ophthalmology, Valencia, Spain; ${ }^{7}$ Hospital de León, Ophthalmology, León, Spain; ${ }^{8}$ Hospital Universitario La Fe, Ophthalmology, Valencia, Spain; ${ }^{9}$ Hospital Universitario IOBA, Ophthalmology, Valladolid, Spain; ${ }^{10}$ Hospital Universitario de Donostia, Rheumatology, San Sebastián, Spain; ${ }^{11}$ Hospital Universitario de Basurto, Rheumatology, Bilbao, Spain; ${ }^{12}$ Hospital Clínico San Carlos, Ophthalmology, Madrid, Spain; ${ }^{13}$ Complejo Hospitalario Universitario de A Coruña, Rheumatology, A Coruña, Spain; ${ }^{14}$ Hospital Doctor Negrín, Rheumatology, Las Palmas de Gran Canaria, Spain; ${ }^{15}$ Hospital Universitario Santiago de Compostela, Rheumatology, A Coruña, Spain; ${ }^{16}$ Hospital Universitario 12 de Octubre, Rheumatology, Madrid, Spain; ${ }^{17}$ Hospital Universitario Fundación de Alcorcón, Rheumatology, Madrid, Spain; ${ }^{18}$ Hospital Universitario Miguel Servet, Ophthalmology, Zaragoza, Spain; ${ }^{19}$ Hospital Puerta del Mar, Rheumatology, Cádiz, Spain; ${ }^{20}$ Hospital Universitario de Bellvitge, Rheumatology, Barcelona, Spain; ${ }^{21}$ Hospital Sierrallana, Rheumatology, Torrelavega, Spain

Background: Posterior segment involvement is the most serious affection of uveitis in Behçet's disease (BD), with cystoid macular edema (CME) being the leading cause of blindness. Anti-TNF, especially adalimumab (ADA) and infliximab (IFX), have demonstrated efficacy as first-line biologic agents in BD-related uveitis [1,2]. Moreover, the anti-IL6R tocilizumab (TCZ) has shown excellent results in highly refractory $B D$-uveitis and noninfectious uveitic CME [3-6].

Objectives: To compare the efficacy of ADA vs IFX vs TCZ in patients with refractory $\mathrm{CME}$ due to $\mathrm{BD}$.
Methods: Observational multicenter study of patients with BD-associated CME refractory to conventional and/or biological immunosuppressive drugs. From a cohort of 177 patients treated with anti-TNF and 14 patients treated with TCZ, we selected those with CME at baseline. CME was defined as macular thickness $>300 \mu \mathrm{m}$ (measured by optic coherence tomography). We analyzed in the 3 groups of treatment (ADA, IFX, TCZ) from baseline up to 4 years the evolution of macular thickness (main outcome) and best-corrected visual acuity (BCVA). Differences between basal and final follow-up were evaluated. Multivariable linear regression was used to assess the differences between the 3 groups.

Results: A total of 49 patients were included. ADA was used in 25 patients (40 eyes with CME), IFX in 15 (21 eyes with CME) and TCZ in 9 (11 eyes with $\mathrm{CME}$ ). No statistically significant baseline differences were observed between the 3 groups (Table) except for previous anti-TNF therapy, which was used only in patients treated with TCZ (5 patients received ADA, 1 received IFX and 2 received both ADA and IFX, in different times). Most patients from all groups had received several conventional immunosuppressive drugs. Biological therapy was used in monotherapy or combined with azathioprine $(n=10,5$ and 1 in ADA, IFX and TCZ group, respectively), cyclosporine $A(n=10,5$ and 1$)$ or methotrexate ( $n=4,2$ and 3 ). Macular thickness progressively decreased in the 3 groups, with no signs of CME after 1 year of treatment. Similarly, BCVA improvement and inflammatory ocular remission was reached in all groups (Figure).

Table 1. Demographic and clinical characteristics of 49 patients with cystoid macular edema due to Behçet's disease receiving ADA, IFX or TCZ.

\begin{tabular}{|c|c|c|c|}
\hline & ADA $(n=25)$ & IFX $(n=15)$ & $\operatorname{TCZ}(n=9)$ \\
\hline Eyes with cystoid macular edema, $n$ & 40 & 21 & 11 \\
\hline Age, years & $41 \pm 11$ & $38 \pm 9$ & $43 \pm 16$ \\
\hline Sex, men/women & $12 / 13$ & $7 / 8$ & $5 / 4$ \\
\hline HLA-B51 +, n & 19 & 10 & 6 \\
\hline $\begin{array}{l}\text { Duration of uveitis before anti-TNF/ anti-IL6R, } \\
\text { months }\end{array}$ & $30[12-82]$ & $15[8-60]$ & $\begin{array}{c}32 \\
{[24-144]}\end{array}$ \\
\hline \multicolumn{4}{|l|}{ Ocular features at start of anti-TNF/anti-IL6R } \\
\hline Macular thickness, $\mu \mathrm{m}$ & $432 \pm 118$ & $483 \pm 126$ & $417 \pm 113$ \\
\hline Visual acuity, BCVA & $0.4 \pm 0.2$ & $0.3 \pm 0.2$ & $0.2 \pm 0.2$ \\
\hline Tyndall, inflammation grade & $2[1-3]$ & $1[0-1.5]$ & $1[0-1.5]$ \\
\hline Vitritis, inflammation grade & $2.5[1.5-3]$ & $1[0-2]$ & $2[1-2]$ \\
\hline \multicolumn{4}{|l|}{ Previous treatment, $\mathrm{n}$} \\
\hline $\begin{array}{l}\text { Oral glucocorticoids // i.v. pulse } \\
\text { methylprednisolone }\end{array}$ & $18 / / 13$ & $4 / / 9$ & $7 / / 8$ \\
\hline MTX //CsA //AZA & $13 / / 22$ // 14 & $8 / / 13 / / 8$ & $8 / / 6 / / 2$ \\
\hline ADA // IFX & $0 / / 0$ & $0 / / 0$ & $7 / / 3$ \\
\hline $\begin{array}{l}\text { Prednisone dosage at start of anti- } \\
\text { TNF/anti-IL6R, mg/day }\end{array}$ & $45[30-60]$ & $30[20-60]$ & $30[30-30]$ \\
\hline \multicolumn{4}{|l|}{ Combined treatment, $\mathrm{n}$} \\
\hline $\mathrm{CsA} / / \mathrm{AZA} / / \mathrm{MTX}$ & $10 / / 10 / / 4$ & $5 / / 5 / / 2$ & $1 / / 1 / / 3$ \\
\hline
\end{tabular}

Data are presented as mean $\pm S D$ or median $[\mathrm{IQR}]$ when data were not normally distributed. ADA, adalimumab; AZA, azathioprine; CsA, cyclosporine A; MTX, methotrexate; IFX, infliximab; TCZ, tocilizumab.
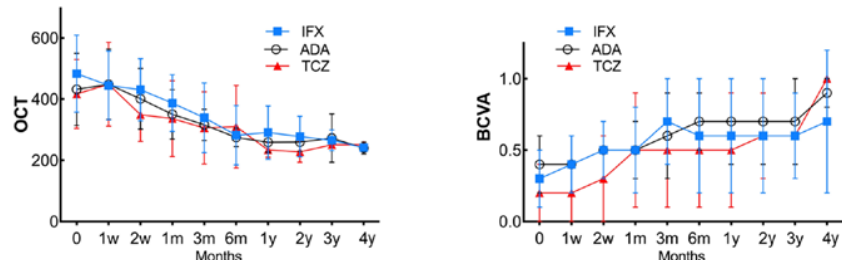

Figure 1. Evolution of ocular parameters in 49 patients with cystoid macular edema due to Behçet's disease receiving ADA, IFX or TCZ.

Conclusion: Refractory CME associated to BD's uveitis can be effectively treated with ADA, IFX or TCZ. Moreover, TCZ is effective in patients resistant to anti-TNF therapy.

\section{REFERENCES:}

[1] Arthritis Rheumatol. 2019;71(12):2081-2089. doi: 10.1002/art.41026

[2] Ophthalmology. 2018;125(9):1444-1451. doi: 10.1016/j.ophtha.2018.02.020

[3]Rheumatology (Oxford). 2018;57(5):856-864. doi: 10.1093/rheumatology/kex480

[4] Am J Ophthalmol.2019;200:85-94. doi: 10.1016/j.ajo.2018.12.019

[5] Clin Exp Rheumatol. 2014;32(4 Suppl 84): S54-7. PMID: 25005576

[6] Clin Exp Rheumatol. 2016;34(6 Suppl 102): S34-S40. PMID:27054359

Disclosure of Interests: None declared

DOI: 10.1136/annrheumdis-2021-eular.307 